\title{
Immunocytokine NHS-IL2-LT
}

National Cancer Institute

\section{Source}

National Cancer Institute. Immunocytokine NHS-IL2-LT. NCI Thesaurus. Code C82411.

A fusion protein consisting of a mouse-human chimeric antibody directed against DNA released by necrotic tumor cells fused to two molecules of a genetically modified human interleukin-2 (IL-2) with potential antineoplastic activity. Upon administration, the antibody moiety of immunocytokine NHS-IL2-LT binds to DNA released by necrotic tumor cells located primarily at the core of necrotic solid tumors, delivering the IL-2 moiety. In turn, the IL-2 moiety of this agent activates the immune system to mount a cytotoxic T lymphocyte response against nearby tumor cells. 